\title{
Chemiluminescence behavior of fluorescent aromatics tethered \\ 9-Methylidene-10-methylacridans involving chemiluminescence resonance energy transfer (CRET) quenching
}

\author{
Takayuki Maruyama ${ }^{\mathrm{a}}$, Hiroaki Sugishita ${ }^{\mathrm{a}}$, Harumi Kujira ${ }^{\mathrm{a}}$, Musubu Ichikawa ${ }^{\mathrm{b}}$ \\ Yoshiyuki Hattori $^{\mathrm{a}}$, Jiro Motoyoshiya ${ }^{\mathrm{a}, *}$
}

a Applied Chemistry Course, Division of Chemistry and Materials, Faculty of Textile Science and Technology, Shinshu University, Ueda, Nagano 386-8567, Japan

${ }^{\mathrm{b}}$ Functional Polymer Science Course, Division of Chemistry and Materials, Faculty of Textile Science and Technology, Shinshu University, Ueda, Nagano 386-8567, Japan

* Corresponding author, Tel.: +81 268 5402; fax: +81 268 5391; E-mail address jmotoyo@shinshu-u.ac.jp

Keywords:

Chemiluminescence

Acridan

Singlet oxygen

Chemiluminescence resonance energy transfer (CRET)

\section{ABSTRACT}

The chemiluminescence (CL) behavior, observed in the singlet oxygenation of three fluorescent aromatics tethered 9-methylidene-10-methylacridans bearing the pyrene, perylene, and stilbene moieties, was investigated. The CL spectrum of 9-(perylen-3'-ylidene)-10-methylacridan displayed a red-shifted emission different from the fluorescent products, while 9-(pyren-1'-ylidene)-10-methylacridan and 9-(4'-styrylbenzylidene)-10-methylacridan produced very weak CLs. A chemiluminescence resonance energy transfer (CRET) quenching of the excited aromatic aldehydes by the acridans remaining as the unreacted reactants was found to result in these unexpected CL behaviors.

Chemiluminescence (CL) during the thermal decomposition of the intermediate acridan-dioxetanes generated by the singlet oxygenation of 9-benzylidene-10-methylacridans has been occasionally investigated, ${ }^{1}$ in which the 
corresponding aldehydes and the fluorescent $N$-methylacridone (NMA), the latter of which is the common emitter, were formed as the decomposition products as shown in Scheme 1. Recently, some new aspects of their CL have been reported. For example, the CL intensity is highly dependent on the substituents attached to the benzylidene moiety, 2 a CIEEL (chemically initiated electron exchange luminescence) is applied to the chemiexcitation process, ${ }^{3}$ and the azacrown ether tethered benzylideneacridan is a potential probe for metal ion sensing based on the interaction between the emitter, the excited NMA, and the metal-coordinated azacrowned benzaldehyde. ${ }^{4}$ The thermal dioxetane decomposition, in principle, produces two carbonyl compounds, one of which is excited and emits light as a visible output if either carbonyl compound is fluorescent. Therefore, it is interesting to explore the chemiluminescent singlet oxygenation of 9-methylidene-10-methylacridans possessing fluorescent moieties because of the possibility of observing the unprecedented CL. In this study, we report the CL behavior observed during the singlet oxygenation of 9-methylidene-10-methylacridans bearing fluorescent moieties such as pyrene, perylene and stilbene moieties, revealing that a chemiluminescence resonance energy transfer (CRET) quenching occurred and provided an unexpected CL behavior different from the known CL of the 9-benzylidene-10-methylacridans.

\section{Scheme 1}

The three acridans, such as 9-(pyren-1'-ylidene)-10-methylacridan (1a), 5 9-(perylen-3'-ylidene)-10-methylacridan (1b), 6 and 9-(4'-styrylbenzylidene)10-methylacridan (1c), 7 were prepared as luminophores by the Horner-Wadsworth-Emmons reaction of the 9-diethylphosphono-10-methylacridan and the corresponding aromatic aldehydes, ${ }^{2,4}$ whose structures are shown in Figure 1 . It is important to note that all the acridans thus prepared are non-fluorescent in spite of having fluorescent moieties probably due to the fluorescence quenching by an intramolecular photo-induced electron transfer (PeT) from the nitrogen atom in the acridan ring to the excited fluorescent moiety. ${ }^{8}$ Although 1a-c have the fully $\pi$-conjugated systems, the preliminary semi-empirical calculations suggested that the methylidene moieties were twisted (Figure1S in Supplementary Data) and the conjugations would be separated between the acridan and the aromatic moieties, which would lead to the intramolecular PeT as can be seen the several fluorescence probes with twisted structures. ${ }^{8 \mathrm{~b}, \mathrm{c}}$ 


\section{Figure 1}

These acridans 1a-c were subjected to the CL reaction by the singlet oxygenation using a combination of hydrogen peroxide and sodium hypochlorite in aqueous THF as the singlet oxygen producing systems. ${ }^{9}$ The CL intensities of $\mathbf{1 a}$ and $\mathbf{1 c}$ were too weak to record their CL spectra, but $\mathbf{1 b}$ gave a CL strong enough to obtain the CL spectrum as shown in Figure 2, which was different from the fluorescence spectra of both decomposition products such as NMA and 3-formylperylene but red-shifted compared to their fluorescences.

\section{Figure 2}

Interestingly, the CL spectrum of $\mathbf{1 b}$ gradually shifted from $538 \mathrm{~nm}$ to $595 \mathrm{~nm}$ (Figure 3a) with the increasing intensity when the concentration of $\mathbf{1 b}$ increased without changing any other conditions. Such a red-shifting emission was also observed in the fluorescence spectrum of the solution after the CL reaction of $\mathbf{1 b}$, in which the intense NMA fluorescence at the low concentration gradually decreased while the fluorescence of 3-formylperylene simultaneously red-shifted from $521 \mathrm{~nm}$ to $587 \mathrm{~nm}$ with the increasing concentration of $\mathbf{1 b}$ as can be seen in Figure 3b. This fluorescence behavior is somewhat complicated, namely, the remarkable decrease in the NMA fluorescence is due to the FRET (fluorescence resonance energy transfer) from the excited NMA to 3-formylperylene as indicated by the large overlapping of the NMA fluorescence and the 3-formylperylene absorption as shown in Figure 4a as well as the excitation and fluorescence spectra shown in Figure 4b and 4c, where the irradiation at $360 \mathrm{~nm}$, at which NMA has a strong absorption but 3-formylperylene a much weaker absorption, increased the fluorescence of 3-formylperylene. In addition, the observed red-shift is caused by some other factor still to be determined. Because there was no significant change in the fluorescence spectrum of 3-formylperylene while changing its concentration, the red-shift due to the excimer formation was excluded. On the other hand, a significant red-shift was observed with the decreasing fluorescence intensity when 3-formylperylene and $\mathbf{1 b}$ were mixed in different ratios (Figure 5), indicating that the large red-shifts were due to the interaction of the excited 3-formylperylene and non-fluorescent $\mathbf{1 b}$. The possibility of an exciplex formation of 3-formylperylene and 1b was investigated by the measurement of the fluorescence lifetimes of the mixed 
solution at various ratios of both compounds. All solutions containing different ratios of 3-formylperylene and $\mathbf{1 b}$ in $\mathrm{THF} / \mathrm{H}_{2} \mathrm{O}(1 / 1)$, at which the red-shift fluorescence was observed, produced lifetimes of 0.25 or $0.26 \mathrm{~ns}$, the same as that for 3-formylperylene (Figure S2 in Supplementary Data), revealing that the exciplex formation between 3-formylperylene and $\mathbf{1 b}$ was also excluded but that the excited species in the CL reaction of $\mathbf{1 b}$ would be 3 -formylperylene in spite of the difference between its fluorescence and CL spectra.

Figure 3, 4, 5

Considering the spectral study described above, we focused our attention on the absorptions of the reactants, 1a-c, having $\lambda_{\max }$. values of $400-450 \mathrm{~nm}$ and found that the absorption spectrum of $\mathbf{1 b}$ overlapped with the blue side of the fluorescence of the 3-formylperylene, while those for 1a and 1c overlapped with large parts of the fluorescences of the corresponding aldehydes as shown in Figure 6. Therefore, for $\mathbf{1 b}$ the excitation energy transfer ${ }^{8}$ from the excited aldehydes to non-fluorescent reactants should cut off part of the fluorescence, and the residual emission led to the apparent red-shift with their decreasing intensities. As observed in Figure 5, for the higher ratios of the reactant $\mathbf{1 b}$, the more red-shifts in the fluorescence of 3-formylperylene were observed with their decreasing intensities. On the other hand, the effective fluorescence quenching would occur for 1a and 1c because of large amounts of overlapping.

\section{Figure 6}

Such changes in the fluorescence spectra prompted us to explore the fluorescence shift by the excitation energy transfer during the interaction with some non-fluorescent dyes but with strong absorptions between 400-650 $\mathrm{nm}$. As expected, the fluorescence shifts of 3-formylperylene were observed by adding four well-known organic dyes such as Congo red, Orange 1, Indigo, and Fast green FCF. Congo red and Orange 1 with absorptions on the blue side of the 3-formylperylene fluorescence shifted its fluorescence from $588 \mathrm{~nm}$ to $597 \mathrm{~nm}$ and from $556 \mathrm{~nm}$ to $568 \mathrm{~nm}$ with the increasing concentration of the dyes as shown in Figure $7 \mathrm{a}$ and $7 \mathrm{~b}$, respectively. In contrast, for other two dyes with their absorptions on the red side of the 3-formylperylene fluorescence, the fluorescence shifted from $543 \mathrm{~nm}$ to $539 \mathrm{~nm}$ by the interaction with Indigo and from $531 \mathrm{~nm}$ to $515 \mathrm{~nm}$ for Fast green FCF as shown in Figure 7c and 7d, 
respectively. Thus, the fluorescence can be not only red-shifted, but also blue-shifted based on the choice of the additive dyes with the absorptions overlapping the fluorescence of the aldehyde. These observations prompted us to examine the effect of the additive dye as a chemical filter in the CL of 1b. As illustrated in Figure 8, Fast green FCF erased the CL emission and the residual emission can be seen at both ends of the emission spectrum when an equimolar amount of the dye toward $\mathbf{1} \mathbf{b}$ was added to the CL system.

\section{Figure 7 and 8}

Now the CL behavior of $\mathbf{1 b}$ can be explained considering the experimental results. There are two ways for the excitation of the carbonyl compounds, NMA or the aldehydes by the decomposition of the intermediate dioxetanes as illustrated in Scheme 2. Although the excited 3-formylperylene might be formed because of their singlet energies lower than NMA as found in their spectra, the initial formation of the excited NMA is anticipated considering the involvement of a CIEEL process for the acridan-dioxetane decomposition as previously documented, in which the initial process is an electron transfer from the nitrogen atom to the dioxetane O-O bonding followed by the cleavage of O-O $\sigma^{*}$ bonding to form the excited NMA and the aldehydes. There are two possibilities for the initial electron transfer from the nitrogen atom of the acridans or from the perylene moiety; namely, the former generates the excited NMA, while the latter directly generates the excited 3-formylperylene. The former is probable because the oxidation potential for the 10-methylacridan was much lower than that of perylene (Figure 3S in Supplementary Data) and as its corroboration the HOMO of $\mathbf{1 b}$ was localized at the acridan region while the LUMO at the perylene moiety (Figure 4S in Supplementary Data). The CRET from the excited NMA to the fluorescent aldehydes followed by the partial CRET quenching cutting off the part of the emission of the aldehydes and leading to the red-shift emission, in which the energy acceptor was the non-fluorescent $\mathbf{1 b}$ still remaining in the reaction mixture as the unreacted reactant. The slight difference in the emission wavelength between the CL and the fluorescence spectra can also be explained by the different ratios of 3-formylperylene and $\mathbf{1 b}$ in the solutions. On the other hand, the very weak CL observed for 1a and 1c would be due to a similar circumstance, in which the emissions from the excited NMA, 1-formylpyrene , or 4-styrylbenzaldehyde were almost erased by the CRET quenching by the reactants 1a and 1c, respectively, because of the large overlapping of the reactant absorptions with the fluorescence of the corresponding aldehydes. CRET is a phenomenon that has been usually observed in some bioluminescence ${ }^{10}$ or suitably constructed CL systems, ${ }^{11}$ but 
the present case is different from this CRET, because the energy acceptor is the non-fluorescent reactants themselves used as the luminophores and act as the partial CL quenchers.

\section{Scheme 2}

In conclusion, the CL behavior of 9-methylideneacridans with the pyrene, perylene, and stilbene moieties (1a-c) during the singlet oxygenation was investigated, and the unexpected CL providing the very weak or red-shifted light emissions was explained by the partial CRET quenching of the excited aldehydes, one of the fluorescent decomposition products, by the unreacted reactants used as the luminophores remaining in the solution. The excitation energy transfer from the fluorescence of 3-formylperylene, the emitter for the CL reaction of $\mathbf{1 b}$, to various commercially available dyes was also studied, in which the fluorescence not only red-, but also blue-shifted depending on the absorption of the additive dyes. The CRET quenching has been only slightly documented ${ }^{12}$, but it is important to design new luminophores. As one of the requirements, the luminophore with little overlapping between its absorption and the emitter fluorescence will be suitable for the efficient CL.

\section{Acknowledgements}

This work was supported by a Grant-in-Aid (19550137) and the Global COE from the Ministry of Education, Culture, Sports, Science and Technology of Japan.

\section{Supplementary data}

Supplementary data (Figure 1S, 2S, and ${ }^{1} \mathrm{H}$ and ${ }^{13} \mathrm{C}$ NMR spectra of 1a-c) associated with this article can be found, in the online version, at

\section{References and notes}

1. (a) McCapra, F.; Beheshti, I.; Burford, A.; Hann, R. A.; Zaklika, K. A. J. Chem. Soc., Chem Commun 1977, 944-946; (b) Chris, L.; Singer, L. A. J. Am. Chem. Soc. 1980, 102, 3823-3829; (c) Sakanishi, K.; Kato, Y.; Mizukoshi, E.; Shimizu, K. Tetrahedron Lett. 1994, 35, 4789-4792; (d) Sakanishi, K.; Nugroho, M. B.; Kato, Y.; Yamazaki, N. Tetrahedron Lett. 1994, 35, 3559-3562; (e) Adam, W. In The chemistry of peroxide; Patai, S., Ed.; John Wiley \& Sons: New York, 1983; pp 829-920.

2. (a) Perkizas, G.; Nikokavouras, J. Monatsh. Chem. 1983, 114, 3-11; (b) Perkizas, G.; 
Nikokavouras, J. Monatsh. Chem. 1986, 117, 89-95.

3. Ciscato, L. F. M. L.; Bartoloni, F. H.; Weiss, D.; Beckert, R.; Baader, W. J. J. Org. Chem. 2010, 75, 6574-6580.

4. Motoyoshiya, J.; Tanaka, T.; Kuroe, M.; Nishii, Y. J. Org. Chem. 2009, 74, 1014-1018.

5. Compound 1a ; A solution of 1-formylpyrene ( $0.49 \mathrm{~g}, 2.1 \mathrm{mmol})$ in THF (12 ml) was added dropwise to a solution of 9-(diethylphosphono)- $N$-methylacridan (0.82 g, 2.6 $\mathrm{mmol})$ and $t$-BuOK (0.32 g, $2.9 \mathrm{mmol})$ in THF $(9 \mathrm{ml})$ and stirred for $3.5 \mathrm{~h}$ at room temperature under a $\mathrm{N}_{2}$ atmosphere. After removal of the solvent and the addition of ethyl acetate, the by-products were removed by washing with water, saturated ammonium chloride aqueous solution and brine. The organic phase was dried over anhydrous $\mathrm{Na}_{2} \mathrm{SO}_{4}$. After the $\mathrm{Na}_{2} \mathrm{SO}_{4}$ was filtered out and the solvent was distilled away, the crude product was purified by the recrystallization with chloroform and methanol to afford an orange crystal. Yield: $85 \%$ (0.74 g); mp 207 $208{ }^{\circ} \mathrm{C} ;{ }^{1} \mathrm{H}$ NMR $\left(400 \mathrm{MHz}, \mathrm{CDCl}_{3}\right) \delta 3.51$ (s, 3H), 6.41 (t, 1H, $J=7.3 \mathrm{~Hz}$ ), 6.90-6.92 (m, 1H), 6.99 (d, $1 \mathrm{H}, J=8.3 \mathrm{~Hz}$ ), 7.02 (d, 1H, $J=8.3 \mathrm{~Hz}$ ), 7.10 (d, 1H, $J=8.4 \mathrm{~Hz}$ ), 7.15 (d, 1H, $J$ = $8.1 \mathrm{~Hz}), 7.35$ (t, 1H, $J=7.5 \mathrm{~Hz}), 7.40$ (s, 1H), 7.85 (d, 1H, $J=7.9 \mathrm{~Hz}), 7.95$ (d, 2H, $J=7.3 \mathrm{~Hz}$ ), 7.97-8.02 (m, 3H), 8.06 (d, 1H, $J=9.0 \mathrm{~Hz}$ ), 8.14 (d, 2H, $J=7.6$ $\mathrm{Hz}), 8.43(\mathrm{~d}, 1 \mathrm{H}, J=9.0 \mathrm{~Hz}) ;{ }^{13} \mathrm{C} \mathrm{NMR}\left(100 \mathrm{MHz}, \mathrm{CDCl}_{3}\right) \delta 34.10,113.05,113.47$, $120.41,120.92,121.78,122.68,124.39,125.05,125.22,125.34,125.40,125.47$, 125.64, 126.29, 126.95, 127.24, 127.38, 127.64, 127.92, 128.76, 128.80, 129.57, 129.65, 130.54, 131.73, 131.89, 133.85, 134.52, 141.69, 143.20; HRMS (ESI): Calcd for $\mathrm{C}_{31} \mathrm{H}_{22} \mathrm{~N}\left([\mathrm{M}+\mathrm{H}]^{+}\right)$: 408.1729, Found: 408.1747 .

6. Compound $\mathbf{1 b}$; This product was prepared in a manner similar to the procedure described above using 3-formylperylene (0.22 g, $0.78 \mathrm{mmol})$ in THF (15 ml), 9-(diethylphosphono)- $N$-methylacridan $(0.31 \mathrm{~g}, 0.94 \mathrm{mmol})$ and and $t$-BuOK (0.18 g, $1.6 \mathrm{mmol})$ in THF (15 ml) for $3 \mathrm{~h}$. Yield: 62\% (0.22 g) as a red crystal; mp 234 $236{ }^{\circ} \mathrm{C}$; ${ }^{1} \mathrm{H}$ NMR $\left(400 \mathrm{MHz}, \mathrm{CDCl}_{3}\right) \delta 3.51(\mathrm{~s}, 3 \mathrm{H}), 6.56(\mathrm{t}, 1 \mathrm{H}, J=7.6 \mathrm{~Hz})$, 6.98-7.05 (m, 3H), 7.07-7.18 (m, 3H), 7.31-7.36 (m, 2H), 7.39-7.48 (m, 2H), 7.49 (t, $1 \mathrm{H}, J=8.0 \mathrm{~Hz}$ ), 7.63 (t, 2H, $J=9.0 \mathrm{~Hz}$ ), 7.90 (dd, 1H, $J=7.9,1.3 \mathrm{~Hz}$ ), 7.97 (d, 1H, $J=7.9 \mathrm{~Hz}$ ), 8.06 (d, 2H, $J=8.1 \mathrm{~Hz}$ ), 8.17 (d, 1H, $J=7.5 \mathrm{~Hz}), 8.20$ (d, 1H, $J=7.5$ $\mathrm{Hz}) ;{ }^{13} \mathrm{C}$ NMR (100 MHz, $\left.\mathrm{CDCl}_{3}\right) \delta 34.07,112.98,113.46,120.31,120.52,120.57$, $120.60,120.62$, 120.90, 121.70, 122.67, 124.30, 125.35, 126.82, 126.97, 126.99, 127.35, 127.87, 128.17, 128.70, 128.77, 129.01, 129.44, 129.54, 130.23, 131.83, 131.87, 132.06, 133.85, 133.88, 135.15, 136.59, 141.65, 143.01; HRMS (ESI): Calcd for $\mathrm{C}_{35} \mathrm{H}_{23} \mathrm{~N}\left([\mathrm{M}]^{+}\right)$: 457.1829, Found: 457.1825 .

7. Compound 1c ; This product was prepared in a manner similar to the procedure 
described above using 4-formyl-(E)-stilbene (0.20 g, $0.96 \mathrm{mmol})$ in THF (15 ml), 9-(diethylphosphono)- $N$-methylacridan $(0.32 \mathrm{~g}, 0.96 \mathrm{mmol})$ and and $t$-BuOK $(0.32 \mathrm{~g}$, $2.9 \mathrm{mmol})$ in THF $(15 \mathrm{ml})$ for $2 \mathrm{~h}$. Yield: $58 \%(0.22 \mathrm{~g})$ as a yellow crystal; $\mathrm{mp} 225^{\circ} \mathrm{C}$ (dec.); ${ }^{1} \mathrm{H}$ NMR (400 MHz, $\mathrm{CDCl}_{3}$ ) $\delta 3.48$ (s, 3H), 6.66 (s, 1H), 6.77 (t, 1H, $J=7.5$ $\mathrm{Hz}$ ), 6.98 (d, 1H, $J=8.3 \mathrm{~Hz}$ ), 7.02-7.07 (m, 4H), 7.21-7.38 (m, 9H), 7.41 (dd 1H, $J$ = 7.8, $1.6 \mathrm{~Hz}$ ), 7.49 (d, 2H, $J=8.3 \mathrm{~Hz}), 7.72(\mathrm{dd}, 1 \mathrm{H}, J=7.9,1.4 \mathrm{~Hz}) ;{ }^{13} \mathrm{C} \mathrm{NMR}$ $\left(100 \mathrm{MHz}, \mathrm{CDCl}_{3}\right) \delta 33.99,112.84,113.72,120.47,121.74,122.59,112.67,123.86$, 126.77, 126.88, 127.19, 127.90, 128.42, 128.44, 128.98, 129.04, 129.10, 129.28, 132.20, 135.71, 137.95, 138.36, 141.62, 143.45; HRMS (ESI): Calcd for $\mathrm{C}_{29} \mathrm{H}_{23} \mathrm{~N}\left([\mathrm{M}]^{+}\right)$: 385.1833, Found: 385.1825.

8. (a) Valeur, B. Molecular Fluorescence: Principles and Applications; Wiley: VCH: Weinheim, 2002; pp 90-94; (b) Gabe, Y; Urano, Y.; Kikuchi, K.; Kojima, H.; Nagano, T. J. Am. Chem. Soc. 2004, 126, 3357-3367; (c) Zhang, X.-F. Photochem. Photobiol. Sci. 2010, 9, 1261-1268.

9. Foote, C.; Wexler, S.; Ando, W.; Higgins, R. J. Am. Chem. Soc. 1968, 90, 975-981.

10. Waud, J. P.; Fajardo, A. B.; Sudhaharan, T.; Trimby, A. R.; Jeffery, J.; Jones, A.; Campbell, A. K. Biochem. J. 2001, 357, 687-697.

11. (a) Teranishi, K. Luminescence 2007, 22, 147-156. (b) Freeman, R.; Liu, X.; Willner, I. J. Am. Chem. Soc. 2011, 133, 11597-11604.

12. Bi, S.; Zhao, T.; Luo, B. Chem. Commun. 2012, 48, 106-108. 


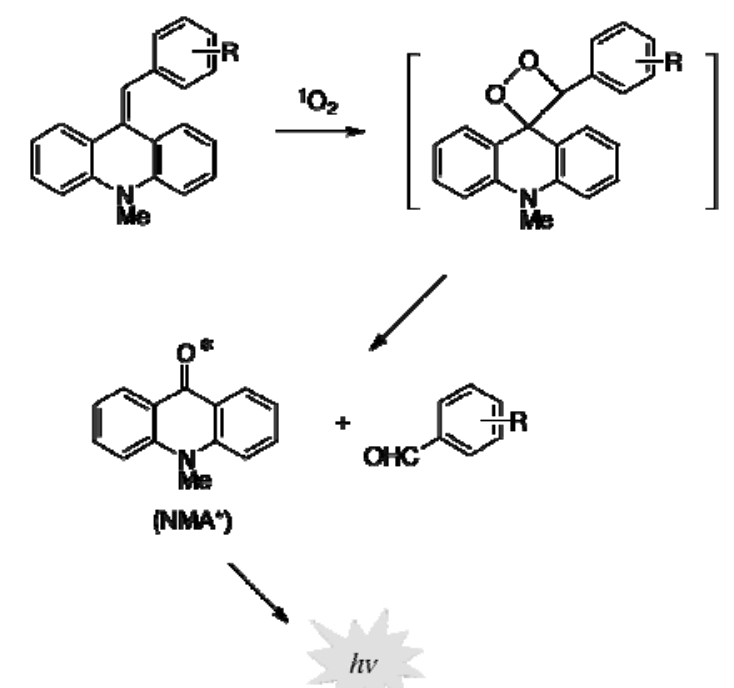

Scheme 1. Chemiluminescence reaction of 9-benzylideneacridans.

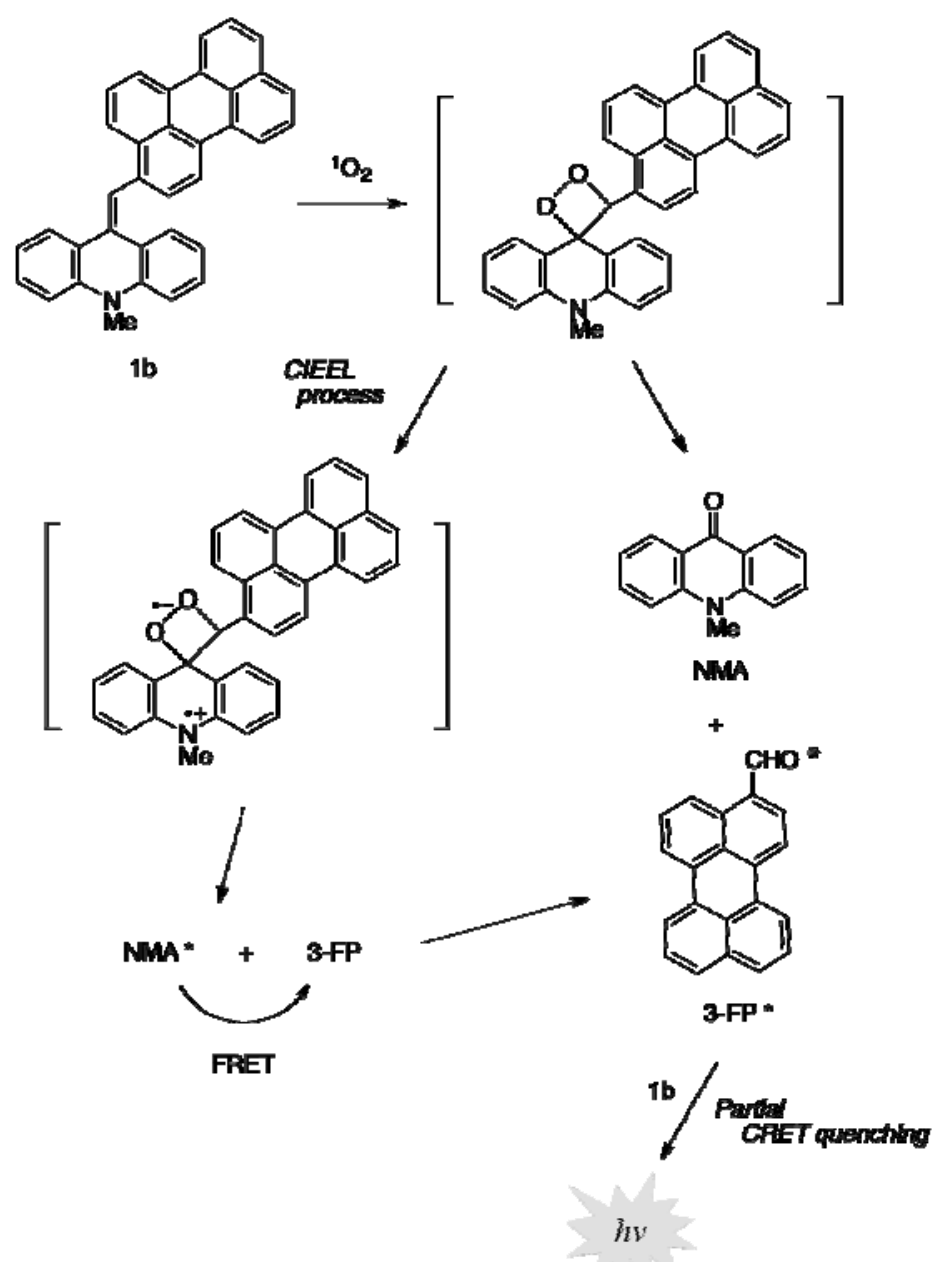

Scheme 2. A plausible pathway of chemiluminescent reaction of $\mathbf{1 b}$ involving a partial CRET quenching. 


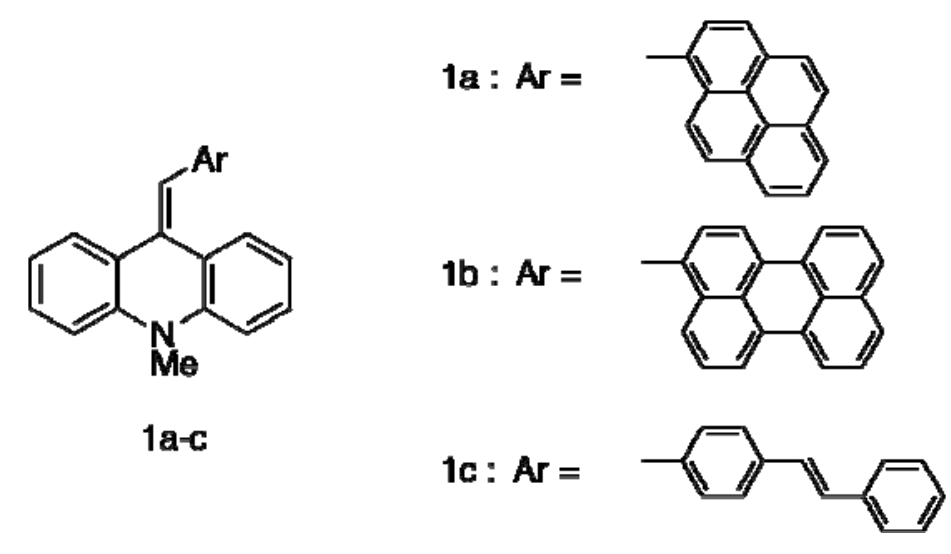

Figure 1. Structures of 9-ylidene-10-methylacridans used in this study.

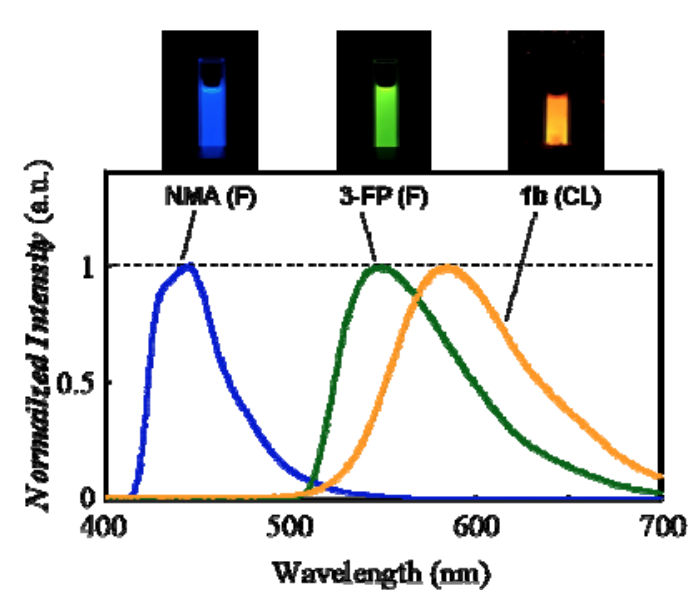

Figure 2. Chemiluluminescence (CL) spectra of acridan $\mathbf{1 b}$ and fluorescence spectra of the degraded products, $\mathrm{N}$-methylacridone (NMA) and 3-formylperylene (3-FP). The CL spectra of 1b; [1 b] $=1.0$ $\times 10^{-3} \mathrm{M},[\mathrm{NaClO}]=3.75 \times 10^{-2} \mathrm{M}$, and $\left[\mathrm{H}_{2} \mathrm{O}_{2}\right]=1.25 \times 10^{-2} \mathrm{M}$. The fluorescence spectra; [3-FP] $=1.0$ $\times 10^{-3} \mathrm{M}$, and $[\mathrm{NMA}]=1.0 \times 10^{-3} \mathrm{M}$ at $\mathrm{EX} \lambda=360 \mathrm{~nm}$ in $\mathrm{THF} / \mathrm{H}_{2} \mathrm{O}(1: 1)$. The picture of the CL was shot by the exposure of $30 \mathrm{sec}$. The fluorescence were shot under UV light irradiation (375 nm). 
(a)
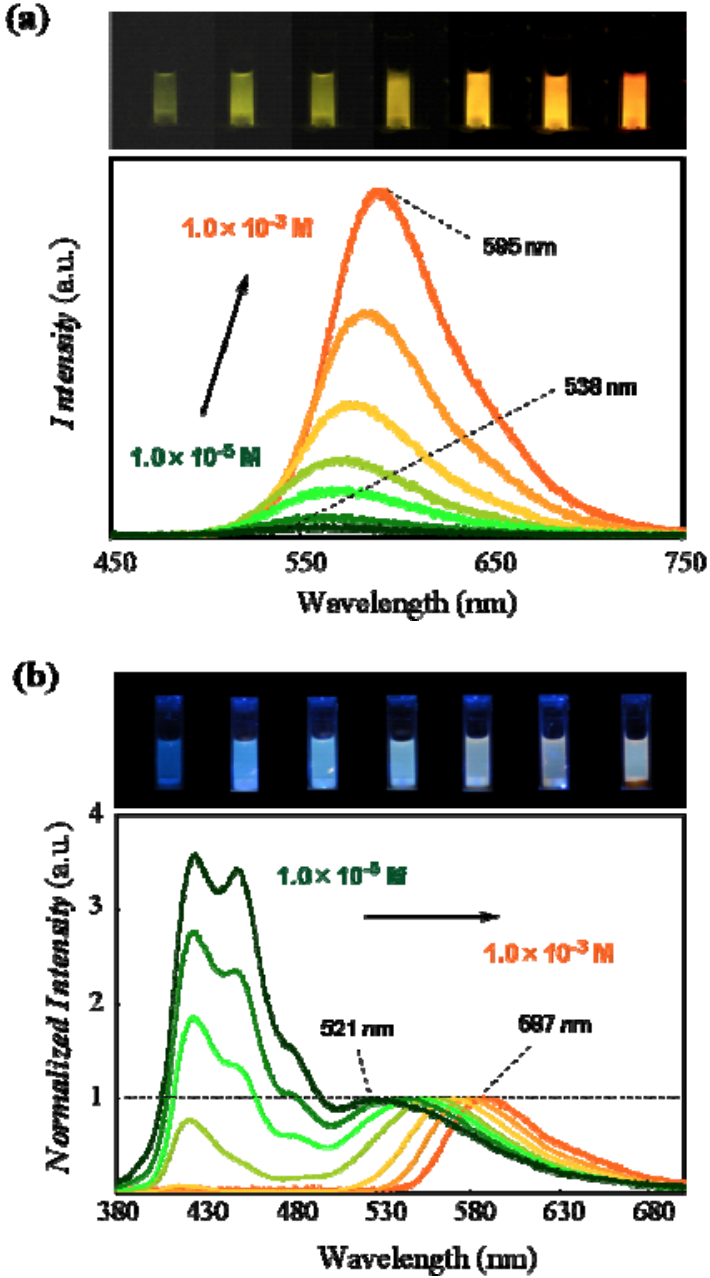

Figure 3. (a) The CL spectra of $\mathbf{1 b}$ with varying its concentration and (b) the normalized fluorescence spectra of the solutions after the CL reaction at $\mathrm{EX} \lambda=360 \mathrm{~nm}$. $[\mathbf{1 b}]=1.0 \times 10^{-5}, 2.5 \times$ $10^{-5}, 5.0 \times 10^{-5}, 1.0 \times 10^{-4}, 2.5 \times 10^{-4}, 5.0 \times 10^{-4}$ and $1.0 \times 10^{-3} \mathrm{M}$ in $\mathrm{THF} / \mathrm{H}_{2} \mathrm{O}$ (1:1). (a) The pictures of the CL were shot by the exposure of $30 \mathrm{sec}$. with correction of the brightness. (b) The fluorescence were shot under UV light irradiation (375 nm). 
(a)

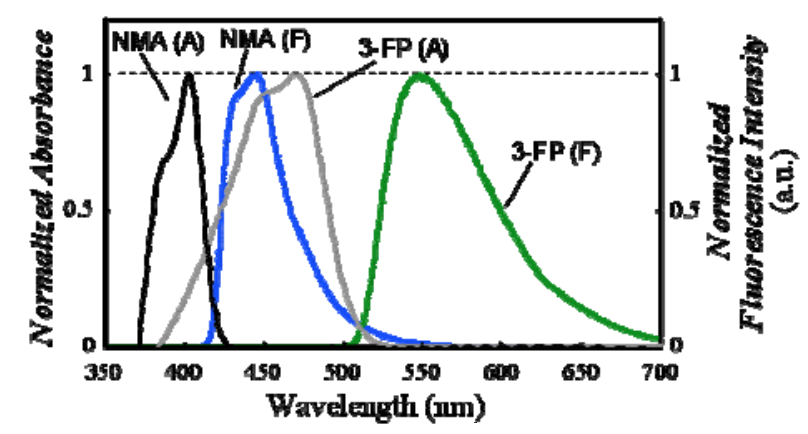

(b)

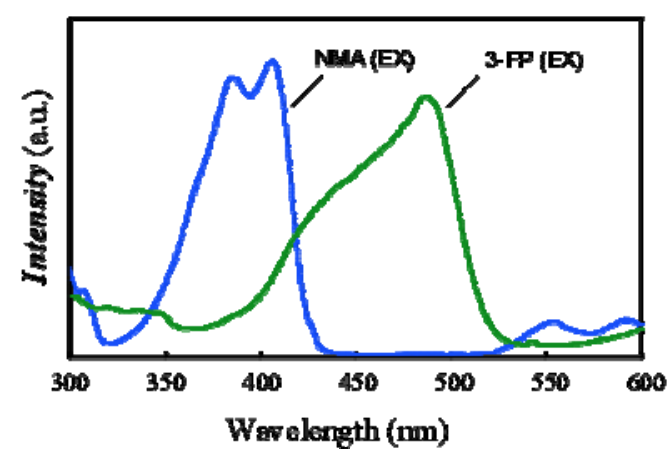

(c)

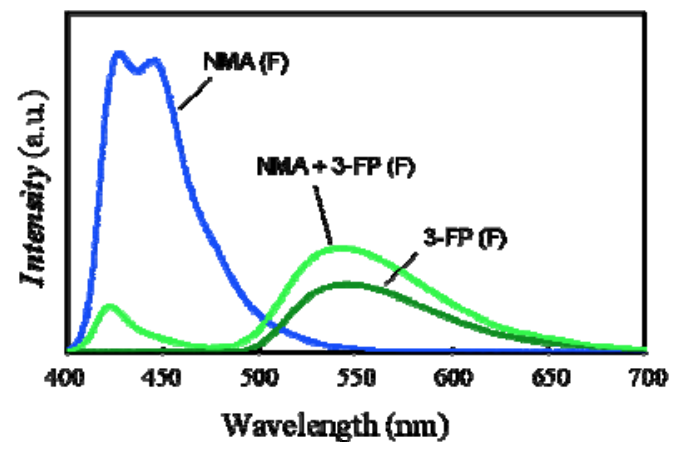

Figure 4. (a) The normalized absorption (A) and fluorescence (F) spectra of $N$-methylacridone (NMA) and 3-formylperylene (3-FP) at EX $\lambda=360 \mathrm{~nm}$. The concentrations were $1.0 \times 10^{-5} \mathrm{M}$ and $1.0 \times 10^{-3} \mathrm{M}$ for the absorption and fluorescence spectra, respectively, in $\mathrm{THF} / \mathrm{H}_{2} \mathrm{O}$ (1:1). (b) Excitation (EX) spectra of NMA and 3-FP. $[\mathrm{NMA}]=[3-\mathrm{FP}]=1.0 \times 10^{-4} \mathrm{M}$. (c) Fluorescence spectra of NMA, 3-FP and the mixture of NMA and 3-FP. EX $\lambda=360 \mathrm{~nm}$. [NMA] $=[3-\mathrm{FP}]=1.0 \times$ $10^{-4} \mathrm{M}$. 


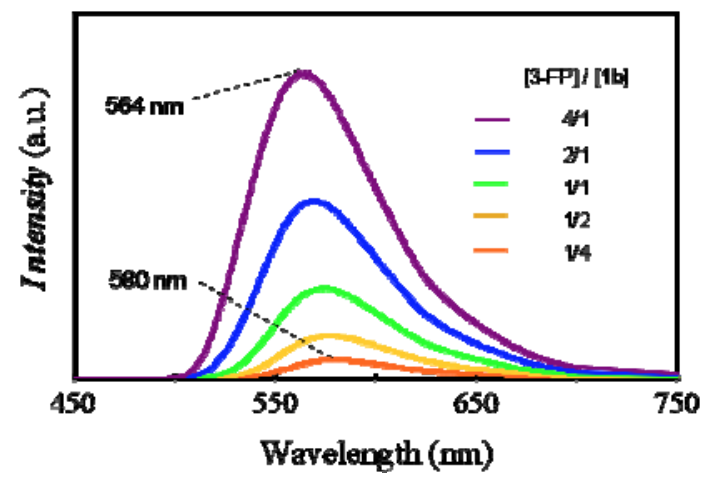

Figure 5. The fluorescence spectra with changing each ratio of the acridans (1a) and 3-formylperylene (3-FP) at $\mathrm{EX} \lambda=360 \mathrm{~nm}$ in THF/ $\mathrm{H}_{2} \mathrm{O}(1: 1)$. [aldehyde] + [acridan] $=5.0 \times 10^{-4} \mathrm{M}$. 
(a)

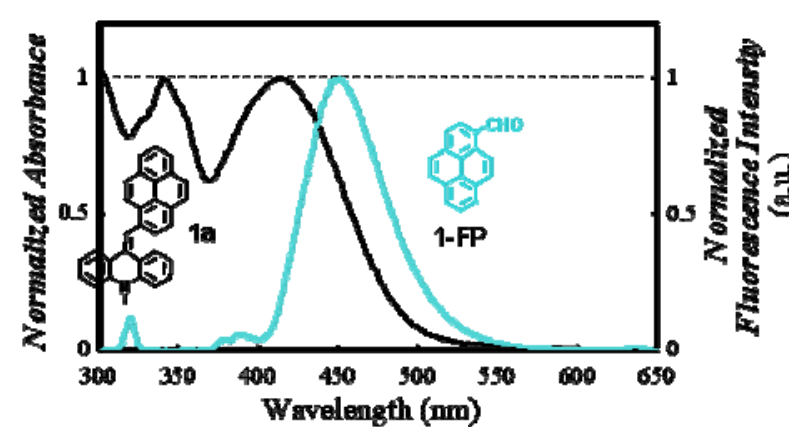

(b)

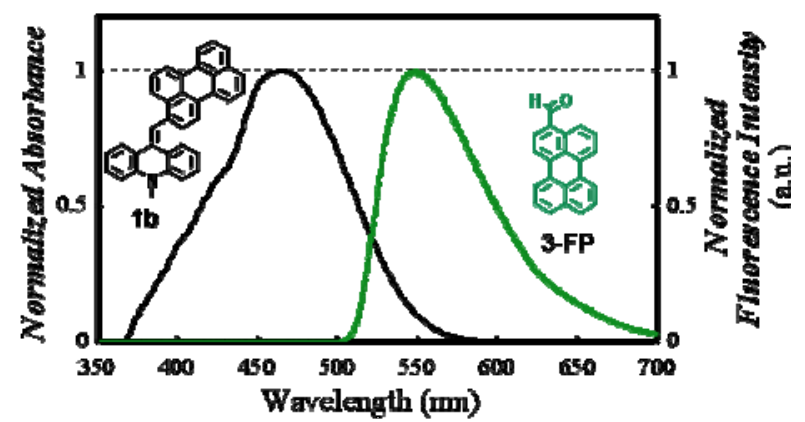

(c)

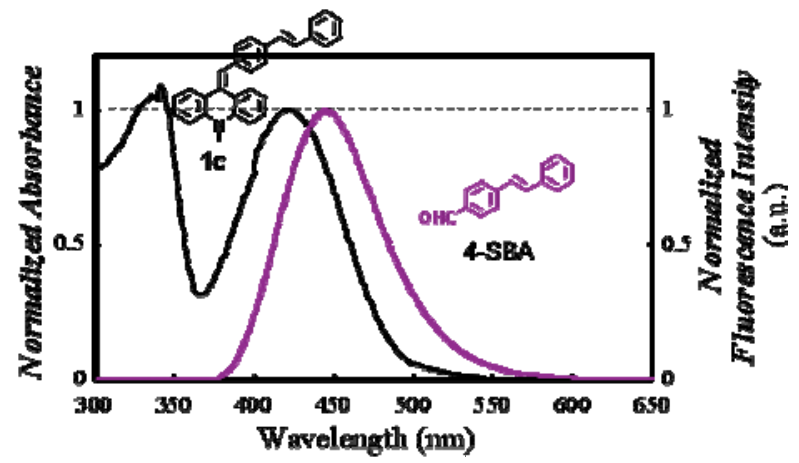

Figure 6. The normalized absorption spectra of the acridans 1a-c, and the normalized fluorescence of the corresponding aldehydes. [acridan] $=1.0 \times 10^{-5} \mathrm{M}$ and [aldehyde] $=1.0 \times 10^{-3} \mathrm{M}$ in THF/ $\mathrm{H}_{2} \mathrm{O}$ $(1: 1)$. 

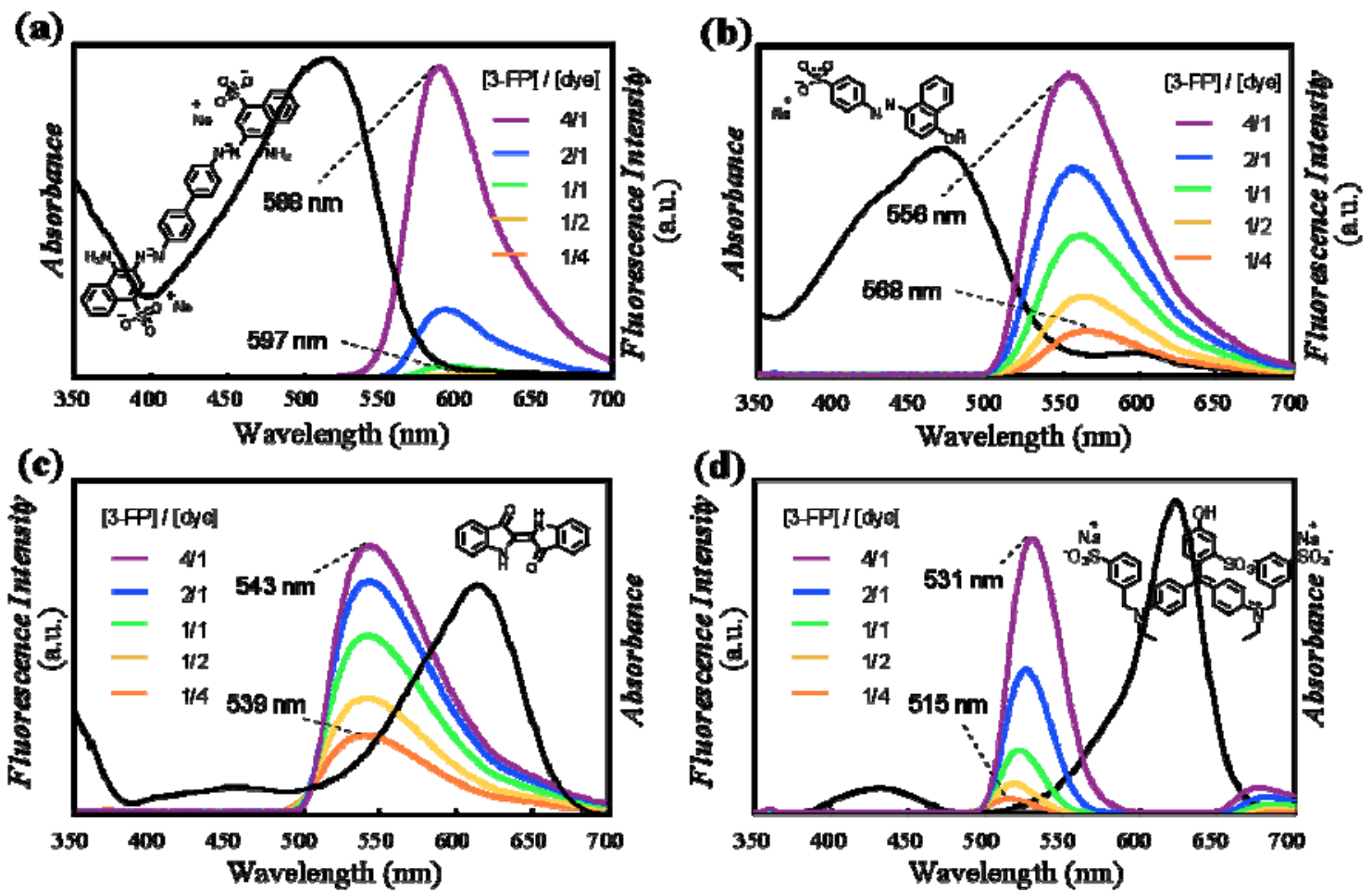

Figure 7. The absorption spectra of (a) Congo red, (b) Orange 1, (c) Indigo and (d) Fast green FCF, and the fluorescence spectra with changing each ratio of 3-formylperylene (3-FP) and these dyes at $\mathrm{EX} \lambda=360 \mathrm{~nm}$. For the absorption spectra, [dye] $=1.0 \times 10^{-5} \mathrm{M}$. For the fluorescence spectra, [3-FP] $+[$ dye $]=5.0 \times 10^{-4} \mathrm{M}$ in $\mathrm{THF} / \mathrm{H}_{2} \mathrm{O}(1: 1)$.

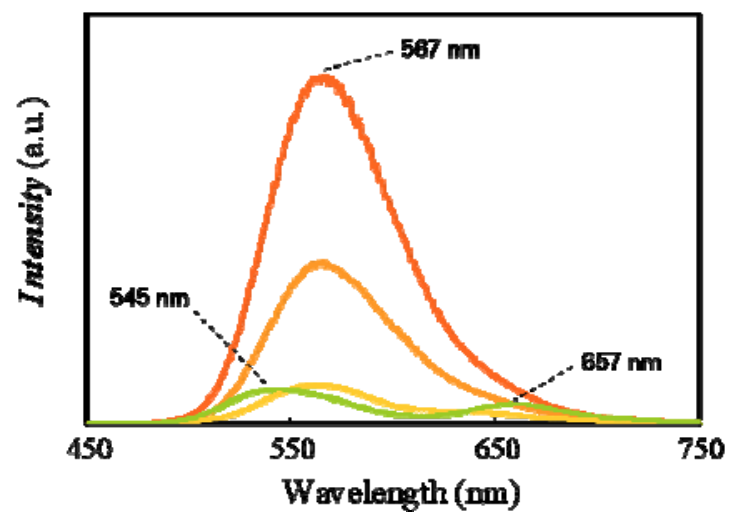

Figure 8. The CL spectra of $1 \mathrm{~b}$ in the presence of Fast green FCF. 